GRASAS Y ACEITES 67 (3)

July-September 2016, e150

ISSN-L: 0017-3495

doi: http://dx.doi.org/10.3989/gya.0216161

\title{
A novel hybrid catalyst for the esterification of high FFA in Jatropha oil for biodiesel production
}

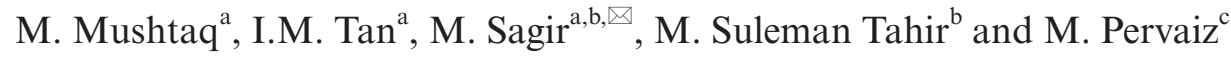 \\ ${ }^{a}$ Chemical Engineering Department, Universiti Teknologi PETRONAS, Bandar Seri Iskandar-31750, Perak, Malaysia. \\ ${ }^{\mathrm{b}}$ Chemical Engineering Department, University of Gujrat, Pakistan. \\ 'Govt. College University Lahore, Pakistan \\ Corresponding author: m.sagir@uog.edu.pk
}

Submitted: 12 February 2016; Accepted: 16 May 2016

SUMMARY: The synthesis and application of a hybrid catalyst for the esterification of free fatty acids (FFA) in Jatropha oil is reported. Three catalysts, namely silica sulfuric acid, silica supported boron trifluoride and a combination of the two in the weight ratio of 1:1, the hybrid catalyst, were investigated. Jatropha oil samples with a wide range of FFA values i.e. 6.64 to $45.64 \%$ were prepared and utilized for the experimental work. This study revealed that silica sulfuric acid and silica supported boron trifluoride were not very effective when used independently. However, a strong synergistic effect was noted in the catalytic activity of the hybrid catalyst which reduced the FFA value from 45.64 to $0.903 \%$ with a conversion efficiency of $98 \%$. Reusability of the catalyst was also tested and the results were promising in up to three cycles of use when used with lower amounts of FFA $(6.64 \%)$ in the oil. Under the influence of the catalyst, the reaction was found to follow first order kinetics. Activation energy was calculated to be $45.42 \mathrm{KJ} \cdot \mathrm{mol}^{-1}$ for $2 \mathrm{wt} . \%$ of hybrid catalyst. The products were analyzed by FT-IR and NMR spectroscopic techniques and the results are reported.

KEYWORDS: Biodiesel; Esterification; Free Fatty Acids; Heterogeneous catalysts; Jatropha oil

RESUMEN: Catalizador novedoso híbrido para la esterificación de aceites de Jatropha con altos contenidos en ácidos grasos libres para la producción de biodiesel. Se aborda la síntesis mediante el uso de un catalizador híbrido en la esterificación de ácidos grasos libres (AGL) de aceites de Jatrofa. Se investigaron tres catalizadores: ácido sulfúrico sobre sílica, trifluoruro de boro sobre sílice y un catalizador híbrido, combinación de los dos anteriores en una relación 1:1en peso. Muestras de aceites de Jatrofa con una amplia gama de valores de FFA: desde 6,64 a 45,64\% se prepararon y se utilizaron en la parte experimental de este trabajo. Este estudio mostró que los soportes de ácido sulfúrico sobre sílica y el de trifluoruro de boro sobre sílice no eran muy eficaces cuando se utilizan de forma independiente. Sin embargo, un fuerte efecto sinérgico se observó en la actividad catalítica del catalizador híbrido que reduce el valor de FFA de 45,64 a 903\% con una eficiencia de conversión del 98\%. La reutilización de catalizador también fue probado y los resultados fueron prometedores hasta tres ciclos de uso cuando se utiliza un aceite con menor cantidad de FFA (6,64\%). Bajo la acción del catalizador, se encontró que la reacción sigue una cinética de primer orden. La energía de activación se calculó y fue de $45,42 \mathrm{~kJ} \cdot \mathrm{mol}^{-1}$ para el catalizador híbrido al $2 \%$ en peso. Se reportan los resultados de los productos analizados por técnicas espectroscópicas FT-IR y RMN.

PALABRAS CLAVE: Aceite de Jatrofa; Ácidos grasos libres; Biodiesel; Catalizadores heterogéneos; Esterificación

Citation/Cómo citar este artículo: Mushtaq M, Tan IM, Sagir M, Suleman Tahir M, Pervaiz M. 2016. A novel hybrid catalyst for the esterification of high FFA in Jatropha oil for biodiesel production. Grasas Aceites 67 (3): e150. doi: http://dx.doi.org/10.3989/gya.0216161.

Copyright: (C) 2016 CSIC. This is an open-access article distributed under the terms of the Creative Commons Attribution-Non Commercial (by-nc) Spain 3.0 Licence. 


\section{INTRODUCTION}

The most convenient feedstock for fatty acid alkyl esters is plant oils and animal fat. It is reported that more than $95 \%$ of biodiesel is being produced from edible oils (Lee et al., 2008; Mushtaq et al., 2013). Continuous usage of these oils for biodiesel and related commercial products may cause a threat to the food market by affecting edible oil's price in the international market. Therefore, it is pertinent to find a feedstock which has no competition with food grade oils. In this context many inedible oils such as Jatropha curcas, Karanja, Neem and Babassu, along with unconventional feedstock, for example, poultry fat, waste cooking oil, algae, fungi, latexes and yellow grease are explored for biodiesel production (Lee et al., 2008; Kim 2009; Shahid and Jamal 2011; Wittayakun et al., 2011; Kevin et al., 2012; Chen et al., 2012; Mushtaq et al.,2013). However, despite having low market value compared to edible oils, the production of biodiesel and alkyl esters from this feedstock is not yet economical due to the presence of high amounts of free fatty acids (FFA). It is generally suggested that the FFA value of feedstock should be less than $0.5-1.0 \%$ for the successful base catalyzed transesterification reaction (Leung and Guo 2006; Aroua et al., 2012). Unfortunately, the FFA value of waste oils and other cheap feedstock sometimes reaches 30\% (Wang et al., 2007). Therefore, a two-step approach is usually applied for biodiesel production; in the first step the FFA value is reduced by using an acid catalysts at less than $1 \%$ and then in the second step, a base catalyzed transesterification step is launched (Tellez et al., 2010; Mushtaq et al., 2014). As methanol is not very reactive with fatty acids under normal processing conditions, acid catalysts are usually employed for the esterification reaction, sometimes at high temperature and pressure conditions.

Although there is not much work reported for solid acid catalysts for the oil esterification process, some notable catalysts reported include Nafionl resins, sulphonated zirconia, suphonated sacharides and tungton oxides (Otadi et al., 2011; Lee et al., 2014; Syam et al., 2016).

For the catalyst in an esterification reaction, BrÖnsted acids such as sulfuric acid, hydrochloric acid, phosphoric acid and Lewis acids such as $\mathrm{BF}_{3}$ and $\mathrm{TiCl}_{4}$ can be used. Sulfuric acid is the most commonly employed catalyst but despite good conversion, its use also presents many problems. A common hurdle is its native acid nature which severely hampers its ease of application. Relatively poor efficiency at lower temperatures and a darkening of the color of the product at higher temperatures are common deficiencies of sulfuric acid use. In addition, removal of the liquid catalyst from the bulk product requires several washing steps (Borges and Díaz 2012) with unfavorably high processing costs.
Due to the above cited reasons, numerous heterogeneous catalysts were proposed for oils possessing high FFA contents. As $\mathrm{BF}_{3}$ and sulfate group based catalysts are found to be effective in many reactions which require acidic or Lewis acid sites for catalysts, it is appropriate to consider new catalyst candidates to further improve the esterification reaction of fatty acids. In heterogeneous catalysts for organic synthesis, silica supported $\mathrm{BF}_{3}$ has been reported by Wilson and Clark (1998). It was reported that this catalyst had very strong Lewis acid $\left(\mathrm{BF}_{3}\right)$ as well as some strong BrÖnsted acid sites. However, despite its great potential for reducing FFA in natural oils, this catalyst has never been used for the esterification reaction of fatty acids in oils and it is pertinent to test the efficiency of this catalyst for FFA reduction.

The current study focuses on the usage of heterogeneous catalysts based on $\mathrm{BF}_{3}$ and $\mathrm{SO}_{3}$ groups attached to silica to esterify very high amounts of FFA to methyl esters. The catalytic activity of these catalysts has been studied for various processing conditions. The effects of methanol concentration as well as various FFA contents in oil have also been described. Kinetics and thermodynamic investigations are also reported.

\section{MATERIALS AND METHODS}

\subsection{Raw material and chemicals}

Jatropha oil was obtained from BATC Development Bhd., Malaysia. Methanol, Sodium sulfate, Silica and hexanes were Analytical Reagent (AR) grades from Fisher Scientific. Boron trifluoride - diethyl etherate complex $\left(50 \% \mathrm{BF}_{3}\right)$, formic acid, sodium bicarbonate and chlorosulfonic acid were obtained from Merck. All materials were used as received without further purification.

\subsection{Preparation of silica supported-BF3 catalyst}

Silica supported-BF $\mathrm{B}_{3}$ (SSB) was prepared according to Wilson and Clark (Wilson and $\mathrm{H}$. Clark 1998). Silica was dried at $300{ }^{\circ} \mathrm{C}$ for 24 hours and then cooled in a desiccator. In a three-neck flask, $10 \mathrm{~g}$ silica was mixed with $100 \mathrm{~mL}$ ethanol and then $40 \mathrm{mmol}$ boron trifluoride - diethyl etherate were added. The mixture was stirred at room temperature for 2 hours. The slurry was dried slowly in a rotary evaporator under vacuum at 50 ${ }^{\circ} \mathrm{C}$. The dried catalyst was stored in a glass bottle with a stopper.

\subsection{Preparation of silica sulfuric acid catalyst}

The silica sulfuric acid (SSA) catalyst was prepared according to Khalifi et al., (2007). To a threeneck flask, $60 \mathrm{~g}$ silica was transferred and $23.3 \mathrm{~g}$ of 
chlorosulfonic acid were added drop by drop in the course of 30 minutes. A mild nitrogen stream was applied to remove hydrogen chloride gas produced during the reaction. The product was agitated to facilitate the reaction and the removal of $\mathrm{HCl}$ gas. The obtained product ( $76 \mathrm{~g}$ ) was stored in a bottle with a stopper.

\subsection{Preparation of hybrid catalyst}

An amount of SSA and SSB was mixed in a 1:1 (weight ratio) to make the hybrid catalyst (HC).

\subsection{Preparation of high FFA Jatropha oil}

The crude Jatropha oil had an FFA value of $6.64 \%$ (as oleic acid). A portion of the oil was converted to its fatty acids by saponification with $\mathrm{NaOH}$ and subsequent treatment with sulfuric acid. The sulfuric acid was removed with repeated washes using distilled water until the $\mathrm{pH}$ of the washings was neutral. The fatty acids were dried at $105^{\circ} \mathrm{C}$. Jatropha oil was spiked with different amounts of fatty acids to obtain FFA values of 9.25, 15.47, $27.85,35.01$ and $45.64 \%$ with corresponding acid values of $18.41,30.79,55.42,69.67$ and $90.88 \mathrm{mg}$ $\mathrm{KOH} \cdot \mathrm{g}^{-1}$ of oil, respectively. In addition, the crude oil with a FFA value of $6.64 \%$ (acid value $13.21 \mathrm{mg}$ $\mathrm{KOH} \cdot \mathrm{g}^{-1}$ oil) was also used in this study.

\subsection{Acid catalyzed esterification reaction}

In a $300 \mathrm{~mL}$ three-neck round-bottom flask, equipped with a magnetic stirrer, coil condenser and thermometer, $50 \mathrm{~g}$ of filtered and dried Jatropha oil were transferred and heated to the required temperature $\left(30-65^{\circ} \mathrm{C}\right)$ with stirring at a fixed speed of $600 \mathrm{rpm}$. In a $250 \mathrm{~mL}$ beaker, the required amount of methanol (1-20 moles with respect to FFA moles of oil) and catalyst (0.5-3.0 wt.\%) were mixed and heated to the required temperature $\left(30-65^{\circ} \mathrm{C}\right)$. Then the methanol-catalyst mixture was transferred to the oil bearing flask and stirring was continued for 30-180 min. Then the mixture was transferred to a separatory funnel to separate the methanol and oil methyl esters. After 30 minutes, the two layers were separated and the oil +FAME layer was washed with warm $\left(55^{\circ} \mathrm{C}\right)$ water till the washings were neutral to $\mathrm{pH}$. The treated oil was dried over anhydrous sodium sulfate.

Base catalyzed trans-esterification of oil. For the base catalyzed esterification, oil with a FFA value of less than $1 \%$ was used. The equipment and process were the same as for the pre-esterification experiment except that 6 moles of methanol were used and a $0.85 \mathrm{wt} . \%$ of sodium methoxide was used in place of the catalysts. The reaction was continued for 60 minutes at $65{ }^{\circ} \mathrm{C}$ and then reaction was stopped. The mixture was transferred to a $500 \mathrm{~mL}$ separatory funnel and kept undisturbed for 2 hours. After that the lower dark glycerine + water layer was separated and a golden yellow layer of FAME was washed with warm $\left(55^{\circ} \mathrm{C}\right)$ water until the washings were neutral to $\mathrm{pH}$. The esters were dried over anhydrous sodium sulfate.

\subsection{Analytical methods}

Biodiesel purity was confirmed in accordance with ASTM D 6584-00 with a Shimadzu GC 2010 system with fitted FID-2010. The fatty ester profile was determined by GC-MS with an Agilent 7890A GC System coupled with an Agilent 5975C inert XL EI/CI MSD with Triple-Axis Detector. The capillary column was BP5, $30 \mathrm{~m} \times 250 \mu \mathrm{m} \times 0.25$ $\mu \mathrm{m}$. The oven temperature program was as follows: 3 min at $100^{\circ} \mathrm{C}, 25^{\circ} \mathrm{C} \cdot \mathrm{min}^{-1}$ to $170^{\circ} \mathrm{C}, 2^{\circ} \mathrm{C} \cdot \mathrm{min}^{-\mathrm{i}}$ to $230{ }^{\circ} \mathrm{C}, 20^{\circ} \mathrm{C} \cdot \mathrm{min}^{-1}$ to $250{ }^{\circ} \mathrm{C}$ and kept at $250^{\circ} \mathrm{C}$ for 10 minutes (Wilson, Smith et al. 1997). Helium was used as the carrier gas with a flow rate of 0.5 $\mathrm{mL} \cdot \mathrm{min}^{-1}$.

The esterification progress was monitored according to the AOCS Official Method $\mathrm{Cd}$ 3a-63. FT-IR spectra were recorded using a Perkin Elmer Spectrum One FT-IR spectrometer equipped with a $\mathrm{ZnSe} 450$ HATR assembly. An average of 30 scans was used with a spectral resolution of $4 \mathrm{~cm}^{-1}$ for the range of $4000-400 \mathrm{~cm}^{-1}$ wave number.

The NMR analysis was performed on a Bruker Ultrashield 400 at $400 \mathrm{MHz}$ and $100 \mathrm{MHz}$ to determine the ${ }^{1} \mathrm{H}$ NMR and ${ }^{13} \mathrm{C}$ NMR spectra, respectively. The solvent used was chloroform-d.

\subsection{Determination of FFA conversion}

The FFA value was determined according to the AOCS Official Method Cd 3a-63. FFA conversion was calculated as:

FFAconversion $=\frac{F F A_{i}-F F A_{t}}{F F A_{i}} \times 100$

Where, $\mathrm{FFA}_{\mathrm{i}}$ refers to initial FFA value (\%) and $\mathrm{FFA}_{t}$ is the FFA value (\%) at a specified time. The reported values are mean values of at least three observations.

\section{RESULTS AND DISCUSSION}

\subsection{Properties of Jatropha oil}

The fatty acid composition of Jatropha oil is presented in Table 1. The major fatty acids are oleic acid, linoleic acid, palmitic acid and stearic acid. Crude oil had an FFA value of $6.64 \%$ and an Iodine value of $102.3 \mathrm{mg} \mathrm{I}_{2} / \mathrm{g}$ oil. 


\subsection{Esterification of FFA with acid catalysts}

The esterification reaction of fatty acids with alcohols requires a catalyst to proceed, as shown below.

$$
\mathrm{R}-\mathrm{COOH}+\mathrm{CH}_{3} \mathrm{OH} \Leftrightarrow \mathrm{R}-\mathrm{COOCH}_{3}+\mathrm{H}_{2} \mathrm{O}
$$

As the methanol is not soluble in Jatropha oil and fatty acids (Zhou et al., 2006), the reaction is heterogeneous in nature. It requires a catalyst, high molar excess of methanol and a higher temperature for the forward reaction.

\subsection{Effect of stirring speed}

The stirring speed is important in heterogeneous systems for better mixing and facilitation in a mass transfer process. It becomes an important factor at lower reaction temperatures. However, at higher temperatures, particularly near the boiling of methanol, the boiling can provide sufficient agitation required for the reaction. It has been shown by several studies that a stirring speed beyond 600 rpm has no significant effect on the conversion (Mbaraka et al., 2003; Berrios et al., 2007; Chung et al., 2008; Zhang and Jiang 2008). Therefore, in this study a fixed stirring speed of $600 \mathrm{rpm}$ was used for all experiments.

\subsection{Effect of reaction temperature}

The esterification reaction is highly dependent on the reaction temperature. Generally for heterogeneous catalysts, the reaction temperature was studied in the range of $45-65^{\circ} \mathrm{C}$ because a higher temperature will require a pressurized setup for synthesis due to the low boiling point of methanol (Shahid and Jamal 2011). At room temperature, the extent of reaction is low (Nakpong and Wootthikanokkhan 2010), which increases with an increase in temperature. A similar pattern of effect of reaction temperature was observed in this study. The reaction rate increased at higher temperatures because the elevated temperature provides sufficient energy as well as reducing the

TABLE 1. Fatty acid composition of Jatropha oil

\begin{tabular}{lcc}
\hline Fatty acids & Common acronym & Composition (wt.\%) \\
Palmitic acid & C16:0 & 13.5 \\
Palmitoleic acid & C16:1 & 0.9 \\
Stearic acid & C18:0 & 7.1 \\
Oleic acid & C18:1 & 44.3 \\
Linoleic acid & C18:2 & 32.8 \\
Others & - & 1.4 \\
\hline
\end{tabular}

viscosity of the oil and FFA, thereby providing better phase mixing. The effect of temperature on FFA conversion for all catalysts is shown in Figure1.The reaction temperature was varied from 30 to $65^{\circ} \mathrm{C}$. The $\mathrm{FFA} / \mathrm{methanol}$ ratio was $1: 20$ and the amount of catalyst used was 2 wt.\% of oil.

It can be observed that the hybrid catalyst (mixture of two catalysts) showed better catalytic activity even at a low reaction temperature. The conversion steadily increases with an increase in temperature and $98.2 \%$ FFA conversion was obtained at $65^{\circ} \mathrm{C}$. The effect of individual catalysts SSA and SSB is somewhat lower than that of the hybrid catalyst and a conversion of $92.2 \%$ and $66.4 \%$ was achieved for SSA and SSB, respectively. The silica supported boron trifluoride is found to possess a lower efficiency compared to silica sulfuric acid. This can be due to the higher apparent acidity of the SSA. The synergistic effect of the hybrid catalyst is probably associated with the additive effect between the very strong Lewis acid capability of $\mathrm{BF}_{3}$ and superior BrÖnsted acidity of $\mathrm{SO}_{3}$.

\subsection{Effect of reaction time}

Reaction time is one of the most important factors affecting the esterification reaction. It is also connected with the reaction temperature. At higher temperatures, relatively short reaction times are sufficient for a maximum conversion. The effect of reaction time with three heterogeneous catalysts is shown in figure 2 . The reaction was conducted at $65{ }^{\circ} \mathrm{C}$ with the FFA/methanol ratio of 1:20. The amount of catalyst used was 2 wt.\% of oil. It was observed that the reaction was completed in 100 minutes for $\mathrm{HC}$, and 120 minutes for both SSA and SSB. HC is superior in performance and $98.4 \%$ conversion is achieved in

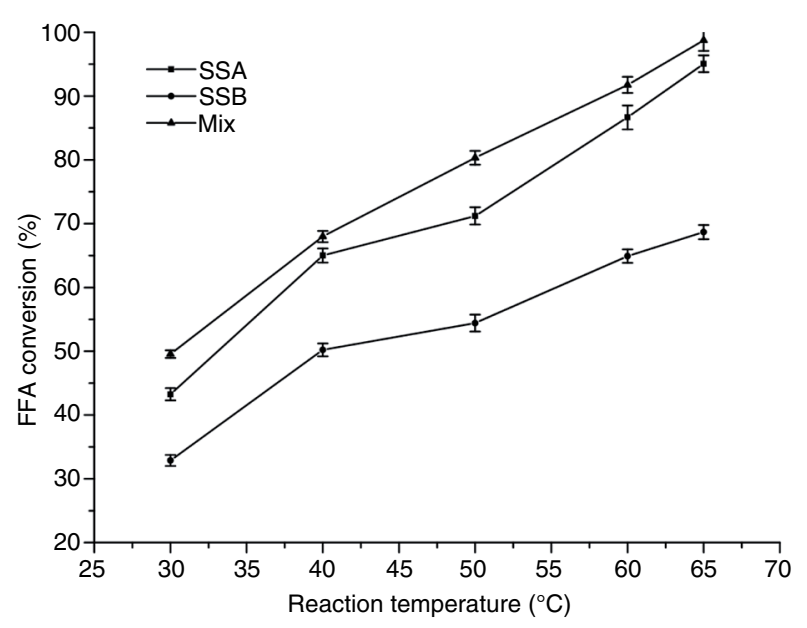

FIGURE 1. Effect of temperature on FFA conversion 


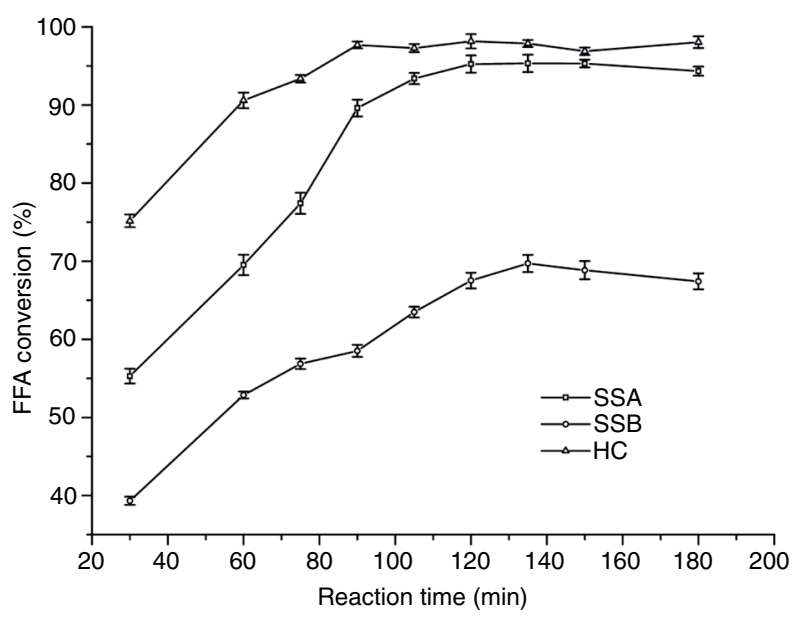

FigURE 2. Effect of reaction time on FFA conversion

a comparatively shorter reaction time of $100 \mathrm{~min}-$ utes. While SSA converted $90.5 \%$ FFA to FAME in 120 minutes, SSB was found to perform poorly with $68.7 \%$ FFA converted to FAME in $120 \mathrm{~min}-$ utes, after which the reaction becomes non progressive. It is again demonstrated that a shorter reaction time for maximum conversion can be attributed to a superior BrÖnsted and Lewis acid capabilities of HC.

\subsection{Effect of methanol molar ratio to FFA}

Methanol is the major reagent in the reaction. As esterification reaction is a reversible reaction, a high molar excess of methanol is required for driving the reaction forward. In many studies a large excess of methanol has been employed, such as 1:50 and 1:60 $[10,28]$. The effect of the amount of methanol is shown in Figure 3. A reaction temperature of $65^{\circ} \mathrm{C}$ was used with $2 \mathrm{wt} . \%$ of catalyst for a reaction time of 120 minutes. It can be seen from Figure 3 that the conversion is very low when a stoichiometric amount (1:1 molar ratio) of methanol is used. At this amount of methanol, all catalysts are almost equal in efficiency, and SSA, SSB and HC showed conversion efficiencies of $26.39 \%, 32.64 \%$ and $33.6 \%$, respectively. However, at higher molar excess, the reaction becomes more efficient and maximum conversion is achieved at FFA:methanol molar ratio of 1:15. The hybrid catalyst efficiently converted $98.11 \%$ of FFA to methyl esters while SSA converted $93.3 \%$. The SSB was lower in performance and a maximum conversion of $68.8 \%$ was achieved at 20 molar excess of methanol. It was found that the $15: 1$ mole ratio of methanol: FFA was sufficient for the maximum conversion and any further increase did not show a progressive effect.

The role of high molar excess of methanol in this context is further discussed in the section 3.8 .

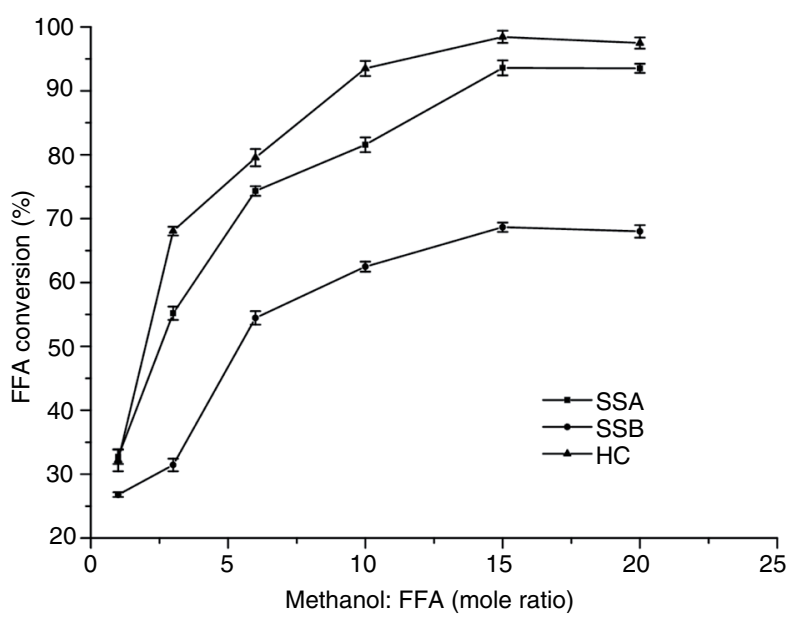

FIGURE 3. Effect of methanol amount on conversion of FFA

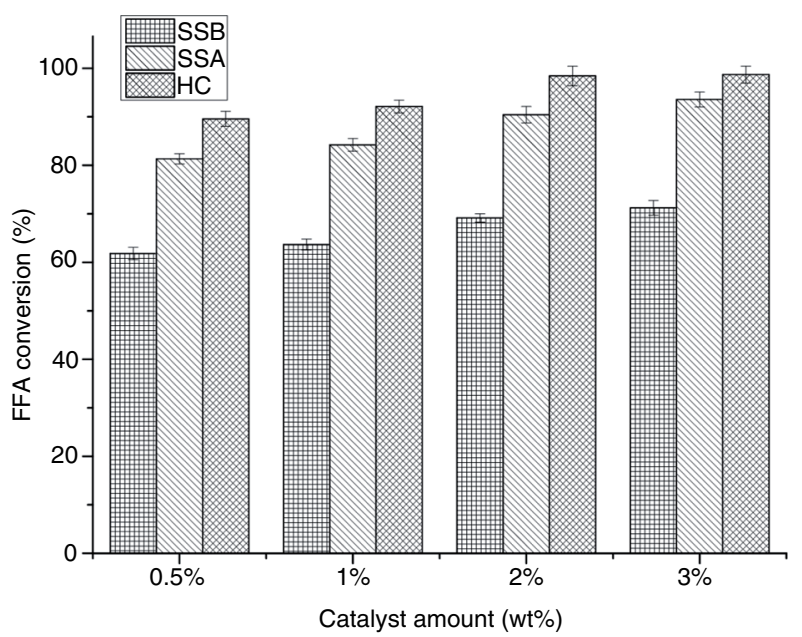

FIGURE 4. Effect of catalyst amount on conversion of FFA

\subsection{Effect of catalyst amount}

Catalyst amount is also an important parameter in the esterification reaction and varying the amount of catalyst shows a noticeable effect (Figure.4). The reaction was studied for FFA conversion by using 1:20 moles of FFA:methanol, a reaction temperature of $65{ }^{\circ} \mathrm{C}$ and a reaction time of 120 minutes. The catalyst amount was varied from 0.5 to $3 \mathrm{wt} . \%$ of oil.

The plot shows the maximum conversion (98.21\%) for HC at 2 wt.\%, and there was no significant effect found for the amount of catalyst exceeding $2 \%$. The SSB and SSA showed a different trend and were lower in performance when compared to the hybrid catalyst even at $3 \mathrm{wt} . \%$ loading. SSB converted $69.2 \%$ FFA at $3 \mathrm{wt} . \%$ and SSA converted $93.6 \%$ FFA at 3 wt. $\%$ amount. 


\subsection{Effect of FFA contents of feedstock and methanol amount}

The cumulative effect of varying the amount of FFA and methanol was also studied. A reaction was conducted at $65^{\circ} \mathrm{C}$ with $2 \mathrm{wt} . \%$ of hybrid catalyst. It was found that the amount of methanol required for maximum conversion was strongly dependent on the initial FFA value of oil. At lower FFA values (6.64 and 9.25\%), a relatively lower FFA:methanol molar ratio (1:6) is sufficient but at higher FFA values, a very high molar ratio of methanol is required (1:15-1:20). The lower molar excess of methanol such as 1:10 and 1:6 are not sufficient for maximum conversion at FFA values of 35.01 and $45.64 \%$. This effect for the hybrid catalyst is presented in figure 5 . It can be observed that the conversion is maximum for molar ratios of 1:15 and 1:20 (FFA:methanol). This requirement of high amounts of methanol may be attributed to the amount of water produced during the esterification reaction. As methanol and water are mutually soluble, a relatively high amount of methanol is required to be available for a successful reaction. Figure 5 also shows that the hybrid catalyst can be used successfully for oils with varying values of FFA.

Re-usability of hybrid catalyst. Re-usability of heterogeneous catalysts is important due to economic and environmental considerations. Before evaluating the re-usability of the hybrid catalyst, the used catalyst was washed with methanol and dried at $40{ }^{\circ} \mathrm{C}$. Dried used catalyst was loaded and the reaction was conducted as described above.

The hybrid catalyst was evaluated for re-usability in two types of oil samples with FFA values of 6.64 and $45.64 \%$. For each type of oil, the same portion of catalyst was used each time. The catalysts for each experiment were used for four times. After

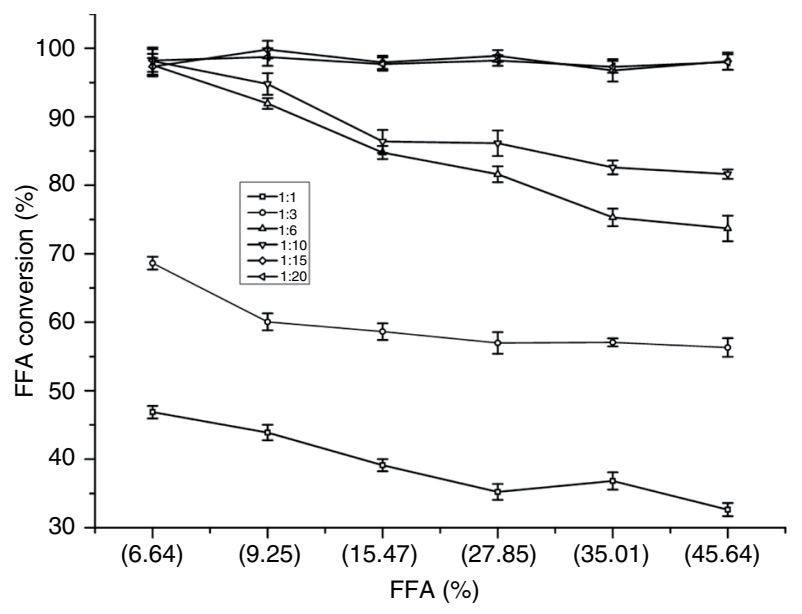

FIGURE 5. Effect of initial FFA amount and methanol / FFA mole ratio on FFA conversion each use, before the next experiment, each catalyst was washed and dried as described above. Results are presented in Figure 6.

Experiments showed that the efficiency of the catalyst was drastically affected when used in the oil with high FFA values $(45.64 \%)$. The efficiency of the catalyst was noted to be $97.5 \%$ when it was new and used for first time in this experiment. In the next experiment, the same catalyst exhibited $66.8 \%$ efficiency, and a significant decrease in catalytic activity was observed. In the next two tests, third and fourth cycle, the efficiency further decreased to $31.2 \%$ and $18.3 \%$ respectively. However, the catalyst was found relatively less effected and maintained its high effectiveness when used with the oil with low $(6.64 \%)$ FFA. For low FFA oil, catalyst efficiency was high $(58.3 \%)$ even for the fourth cycle of usage.

The substantial effect on catalyst efficiency with oil of high amounts of FFA was probably due to the production of high amounts of water during the reaction. The catalyst probably lost its one or both effective groups in water at high temperatures and its efficiency drastically reduced in subsequent cycles.

\subsection{Base catalyzed transesterification}

A very small amount of triglycerides can be converted to methyl esters by using an acid catalyst. Therefore, base catalyzed transesterification was performed by the method discussed earlier, using sodium methoxide. It was noted that the pre-treated oil was found to be suitable for the transesterification reaction and a high conversion of oil to methyl esters, $93.12 \%$, was achieved. A few important properties of the obtained methyl esters are presented in Table 2.

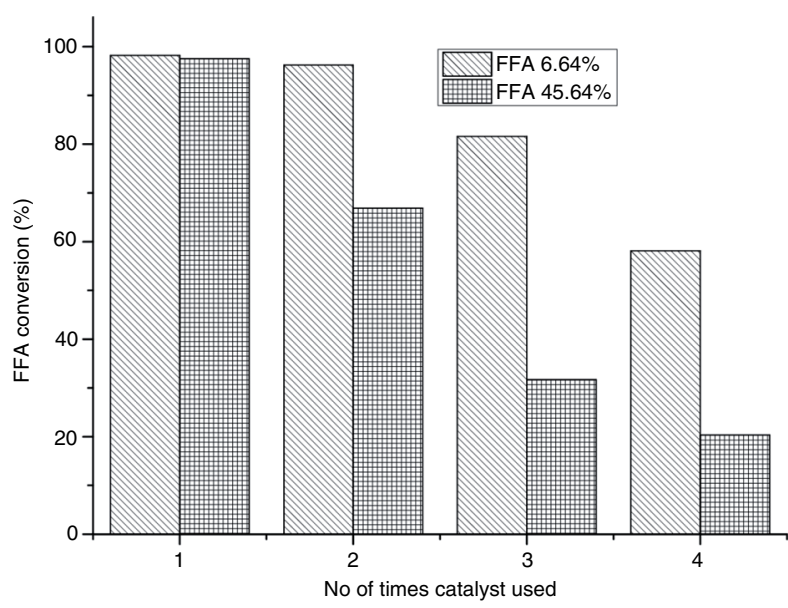

FIGURE 6. Reusability of catalyst with oils having different FFA values 
TABLE 2. Properties of Methyl esters

\begin{tabular}{ll}
\hline Properties & \multicolumn{1}{c}{ Jatropha biodiesel } \\
\hline Methyl esters & $99.1 \%$ \\
Monoglycerides & $112 \mathrm{ppm}$ \\
Diglycerides & $86 \mathrm{ppm}$ \\
Triglycerides & $321 \mathrm{ppm}$ \\
Free glycerol & $183 \mathrm{ppm}$ \\
Density $\left(\mathbf{2 5}{ }^{\circ} \mathbf{C}\right)$ & $0.8271 \mathrm{~g} \cdot \mathrm{mL}^{-1}$ \\
Kinematic viscosity $\left.\mathbf{( 4 0}{ }^{\circ} \mathbf{C}\right)$ & $4.11 \mathrm{~mm}^{2} \cdot \mathrm{s}^{-1}$ \\
Cloud point & $2{ }^{\circ} \mathrm{C}$ \\
Pour point & $0{ }^{\circ} \mathrm{C}$ \\
Iodine value & $99.27 \mathrm{~g} \mathrm{I} \cdot 100 \mathrm{~g}^{-1}$ \\
Acid value & $0.18 \mathrm{mg} \mathrm{KOH} \cdot \mathrm{g}^{-1}$ \\
Moisture & $162 \mathrm{ppm}$ \\
\hline
\end{tabular}

\subsection{Spectroscopic analysis}

\subsubsection{FT-IR Analysis}

FT-IR spectra were recorded for the crude oil, oil with FFA and produced biodiesel. A transmittance band for carbonyl group in fatty acids appears at $1711 \mathrm{~cm}^{-1}$ (a) and for methyl esters (and oils) at $1746 \mathrm{~cm}^{-1}$ (Guillén and Cabo 1997). In addition, fatty acids show a typical broad band at around $3100 \mathrm{~cm}^{-1}$ (b) while in methyl esters (and oils), this band is absent. These bands were observed during the esterification reaction with the hybrid catalyst. In the course of the reaction, samples were drawn and their FT-IR spectra were recorded after several cleaning steps. As can be observed in figure 7, the bands at $1708 \mathrm{~cm}^{-1}$ (a) and $3100 \mathrm{~cm}^{-1}$ (b) are distinctly visible when the oil has a FFA value of $45.64 \%$ (A). However, after 30 minutes the FFA value was reduced to $15 \%$ and bands (a \& b) at 1708 and $3100 \mathrm{~cm}^{-1}$ were reduced in intensity (B). These bands further decreased in intensity (C) to a barely visible shoulder and later diminished (D) where the FFA value became less than $1 \%$. The band at 1742 $\mathrm{cm}^{-1}$ is for the ester carbonyl group. Further details of the FT-IR spectra are presented below.

Oil: $3007 \mathrm{~cm}^{-1}$ (=C-H cis stretch), 2923, $2852\left(\mathrm{CH}_{2}\right.$ stretch), 1746 (ester $\mathrm{C}=\mathrm{O}), 1711$ (acid $\mathrm{C}=\mathrm{O}$ ), $1654(-\mathrm{C}=\mathrm{C}-$ stretch $), 1460\left(-\mathrm{C}-\mathrm{H}\right.$ bend from $\mathrm{CH}_{2}$, $\left.\mathrm{CH}_{3}\right), 1419$ (=C-H bend), $1376\left(\mathrm{CH}_{3}\right.$ sym bend), 1240, 1165, 1118 (ester CO stretch),1099 (C-O stretch), 970 (-HC $=\mathrm{CH}$ - bend $721\left(\mathrm{CH}_{2}\right.$ rocking).

Methyl esters: $3006 \mathrm{~cm}^{-1}$ (=C-H cis stretch), 2924, 2853 $\left(\mathrm{CH}_{2}\right.$ stretch), 1742 (ester $\left.\mathrm{C}=\mathrm{O}\right), 1654(-\mathrm{C}=\mathrm{C}$ stretch),1459 (-C-H bend from $\left.\mathrm{CH}_{2}, \mathrm{CH}_{3}\right), 1435$ (C-H asymm and symm bend of $\left.\mathrm{CH}_{3}-\mathrm{COO}\right), 1376$ ( $\mathrm{CH}_{3}$ sym bend), 1361 (-C-H bend), 1244, 1195, 1169 (ester $\mathrm{CO}$ stretch),1016 (O-C-C stretch), $722\left(\mathrm{CH}_{2}\right.$ rocking).

\subsubsection{NMR analysis}

NMR spectroscopy is a more powerful technique than FT-IR spectroscopy in terms of the structural elucidation of molecules. There are several obvious differences in the spectra of oil and methyl esters. In the ${ }^{1} \mathrm{H}$ NMR spectra, glyceryl protons appear at 4.1 and $4.3 \mathrm{ppm}$ in the form of typically shaped closely spaced peaks (both quintets). The presence of these peaks in a spectrum is a confirmed indication of the presence of glycerides. In the methyl esters, these peaks are absent. Therefore, it is a quick test for the presence of glycerides in the sample.

A comparison of the ${ }^{1} \mathrm{H}$ NMR spectra of Jatropha oil and methyl esters is shown in Figure 8. A small peak at 3.62 which is due to protons of methyl ester is present in the spectrum of Jatropha oil. These methyl esters are due to the conversion of FFA to methyl esters with a heterogeneous catalyst.

The details of all peaks are presented below:

Jatropha oil (treated and contains very low FFA):

${ }^{1} \mathbf{H}$ NMR $\left(\mathrm{CDCl}_{3}\right) \delta \quad 0.88-0.91 \quad\left(-\mathrm{CH}_{3}\right), 1.32-1.64$ $\left(\mathrm{CH}_{2}\right), 1.62\left(\mathrm{CH}_{2}-\mathrm{CH}_{2} \mathrm{COOCH}_{3}\right)$ 2.06-2.07(- $\mathrm{CH}_{2}-$ $\mathrm{CH}=\mathrm{CH}-), 2.29-2.33\left(\mathrm{CH}_{2} \mathrm{COOCH}_{3}\right) 2.81(-\mathrm{CH}=\mathrm{CH}-$ $\left.\mathrm{CH}_{2}-\mathrm{CH}=\mathrm{CH}-\right), 3.62$ (C-OO- $\left.\mathrm{CH}_{3}\right) 4.23$ (glycerin protons), $5.32(-\mathrm{CH}=\mathrm{CH}-)$

${ }^{13} \mathrm{C}$ NMR $\left(\mathrm{CDCl}_{3}\right)$ 14.43-14.46 $\left(-\mathrm{CH}_{3}\right), 23.29-34.37$ $\left(\mathrm{CH}_{2}\right), 61.3$ (C1, C3 glycerol), 69.7 (C2 glycerol) 129$131\left(\boldsymbol{C H}=\boldsymbol{C H},\left(-\boldsymbol{C H}=\boldsymbol{C H}-\mathrm{CH}_{2}-\boldsymbol{C H}=\boldsymbol{C H}-\right), 173.91\right.$ $\left(-\mathrm{COO}-\mathrm{CH}_{3}\right)$.

\section{Methyl Esters:}

${ }^{1} \mathbf{H}$ NMR $\left(\mathrm{CDCl}_{3}\right) \delta$ 0.89-0.93 $\left(-\mathrm{CH}_{3}\right), 1.33-1.63$ $\left(\mathrm{CH}_{2}\right), 1.63\left(\mathrm{CH}_{2}-\mathrm{CH}_{2} \mathrm{COOCH}_{3}\right)$ 2.06-2.07(- $\mathrm{CH}_{2}-$ $\mathrm{CH}=\mathrm{CH}-), 2.28-2.32\left(\mathrm{CH}_{2} \mathrm{COOCH}_{3}\right) 2.82(-\mathrm{CH}=\mathrm{CH}-$ $\left.\mathrm{CH}_{2}-\mathrm{CH}=\mathrm{CH}-\right), 3.62\left(\mathrm{C}-\mathrm{OO}-\mathrm{CH}_{3}\right), 5.31(-\mathrm{CH}=\mathrm{CH}-)$

${ }^{13} \mathrm{C}$ NMR $\left(\mathrm{CDCl}_{3}\right)$ 14.42-14.45 $\left(-\mathrm{CH}_{3}\right), \quad 23.29-$ $34.37\left(\mathrm{CH}_{2}\right), 51.43\left(\mathrm{COOCH}_{3}\right), 128-130(\boldsymbol{C H}=\boldsymbol{C H}$, $\left(-\mathrm{CH}=\mathrm{CH}-\mathrm{CH}_{2}-\mathrm{CH}=\mathrm{CH}-\right) 173.97\left(-\mathrm{COO}-\mathrm{CH}_{3}\right)$.

\subsection{Kinetic studies}

The esterification reaction of FFA with a large excess of methanol in oil is reported to be of first order (Berrios et al., 2007; Borges and Díaz 2012; Fernandes, et al., 2012, Sagir et al., 2013). The kinetic studies on the esterification reaction are discussed here for the hybrid catalyst. As the reaction rate is dependent on the reaction time and temperature, various experiments at specific reaction temperature for 180 minutes were performed. It was found that the conversion reached a constant level after 100 minutes of reaction time (Figure 9). At a high reaction temperature, the reaction rate was noticeably high. The data obtained from the plot (shown in Figure 10) were used to calculate the rate 


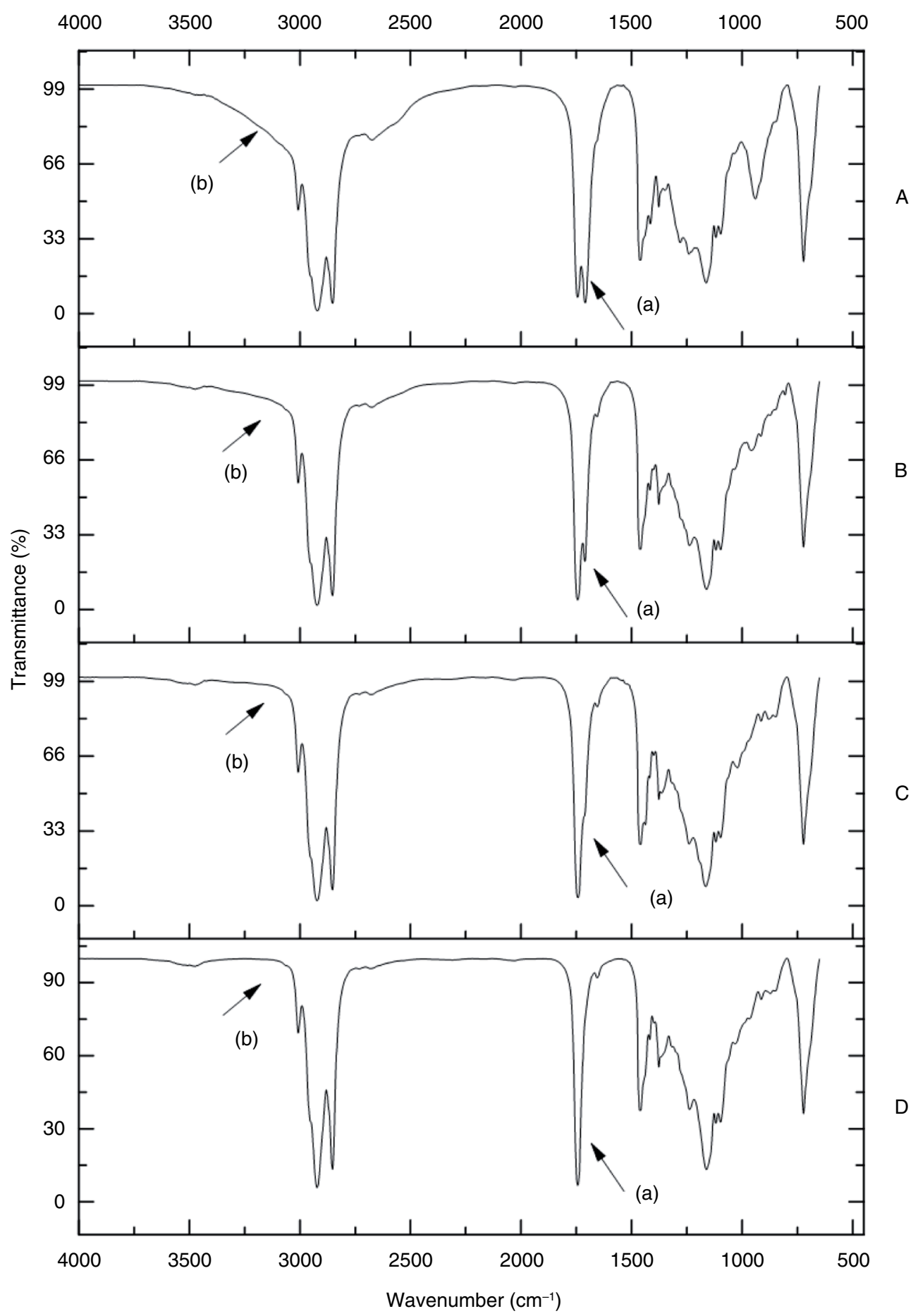

FIGURE 7. FT-IR spectra showing the course of FFA conversion reaction

constant (K) by using linear regression (equation 2) (Fernandes et al., 2012):

$$
\ln \frac{[F F A]_{t}}{[F F A]_{i}}=-K t
$$

where [FFA]i and [FFA]t are the FFA values at the start and at a particular time, respectively.

$\ln [\mathrm{FFA}] \mathrm{t} /[\mathrm{FFA}] \mathrm{i}$ and time (s) were plotted for all temperatures and a linear regression of each curve was used to calculate the value of $\mathrm{K}$. The results are presented in Table 3 . The high values of linear 


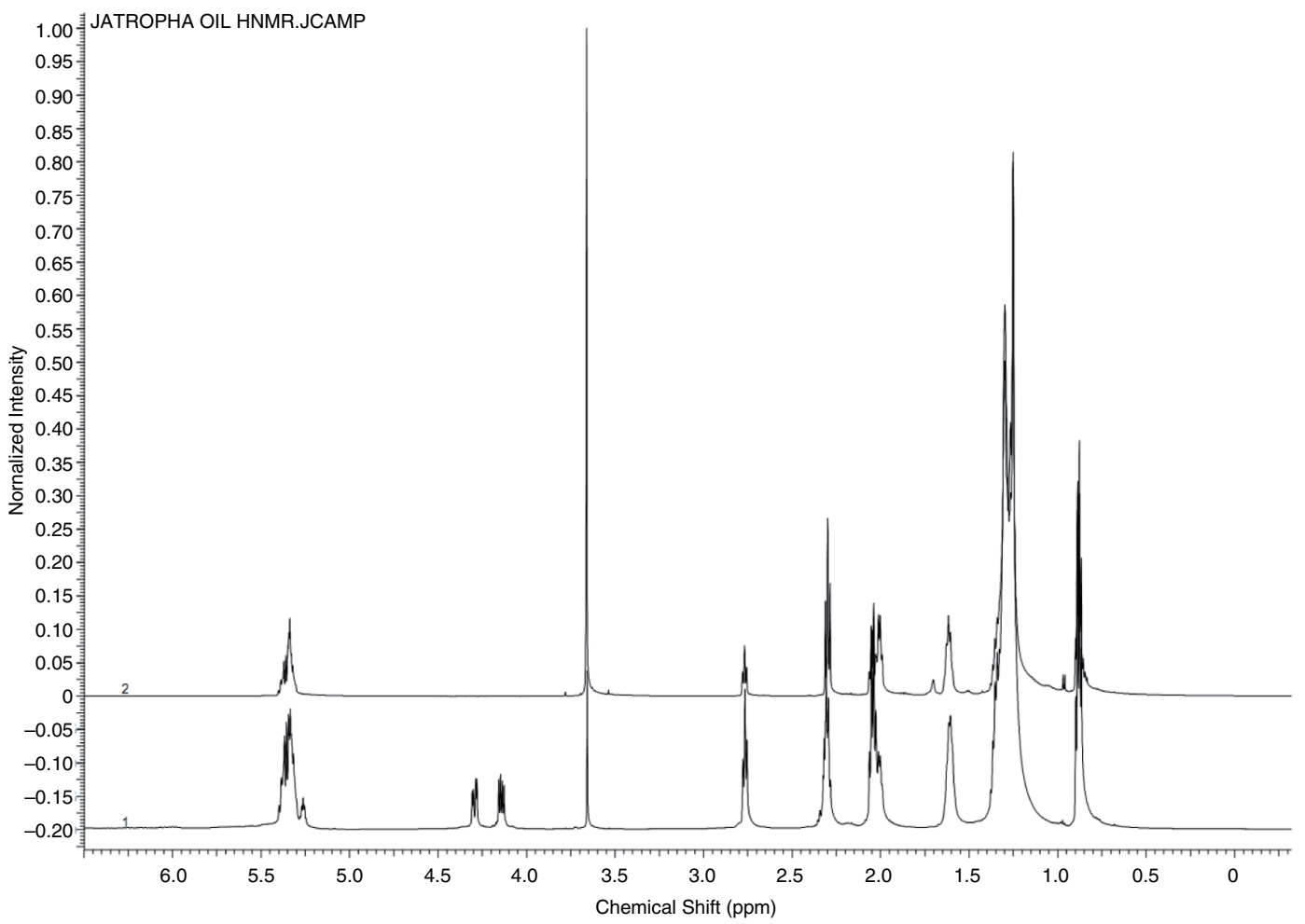

FIGURE 8. Comparison of 1H NMR spectra of treated Jatropha oil and its methyl esters

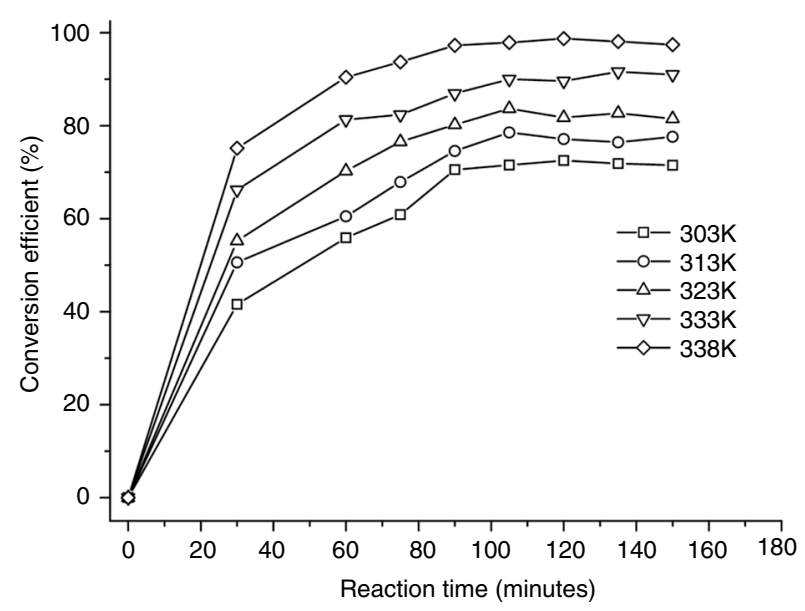

FIGURE 9. Effect of reaction time at different reaction temperatures on FFA conversion

TABLE 3. Reaction rate constants at different temperatures

\begin{tabular}{lcc}
\hline $\begin{array}{l}\text { Temperature } \\
(\mathbf{K})\end{array}$ & $\begin{array}{c}\text { Rate } \\
\text { constant K }\left(\mathbf{s}^{-\mathbf{1}}\right)\end{array}$ & $\begin{array}{c}\text { Correlation } \\
\text { coefficient }\left(\mathbf{R}^{\mathbf{2}}\right)\end{array}$ \\
\hline 303 & $1.09 \times 10^{-4}$ & 0.9876 \\
313 & $1.74 \times 10^{-4}$ & 0.9894 \\
323 & $2.94 \times 10^{-4}$ & 0.9969 \\
333 & $4.95 \times 10^{-4}$ & 0.9937 \\
338 & $7.30 \times 10^{-4}$ & 0.9965 \\
\hline
\end{tabular}

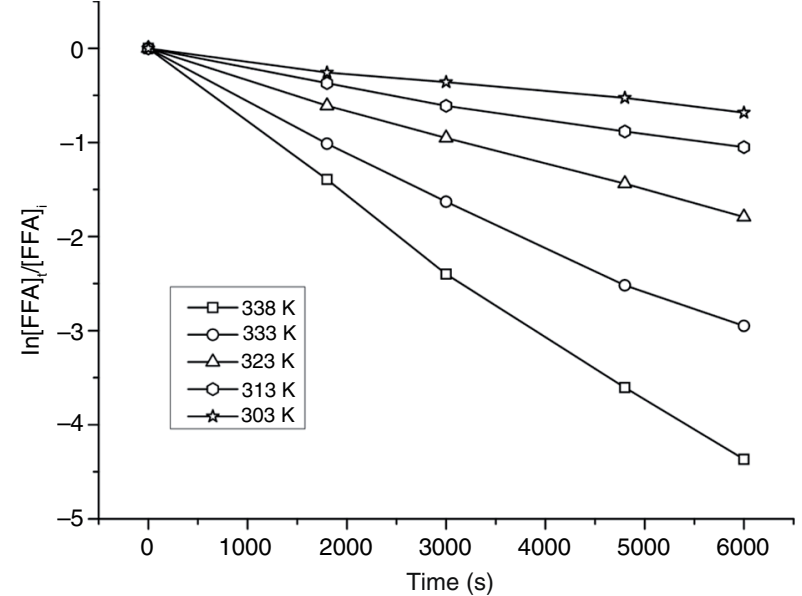

FIGURE 10. Plot between $\ln [\mathrm{FFA}] \mathrm{t} /[\mathrm{FFA}] \mathrm{i}$ and reaction time (s)

correlation coefficient $\left(\mathrm{R}^{2}\right)$ indicate that the reaction follows a first order kinetics (Fernandes, Cardoso et al. 2012).

The activation energy (Ea) was calculated by using the Arrhenius equation:

$$
\ln K=\ln A-\left(\frac{E_{a}}{R}\right) \times\left(\frac{1}{T}\right)
$$




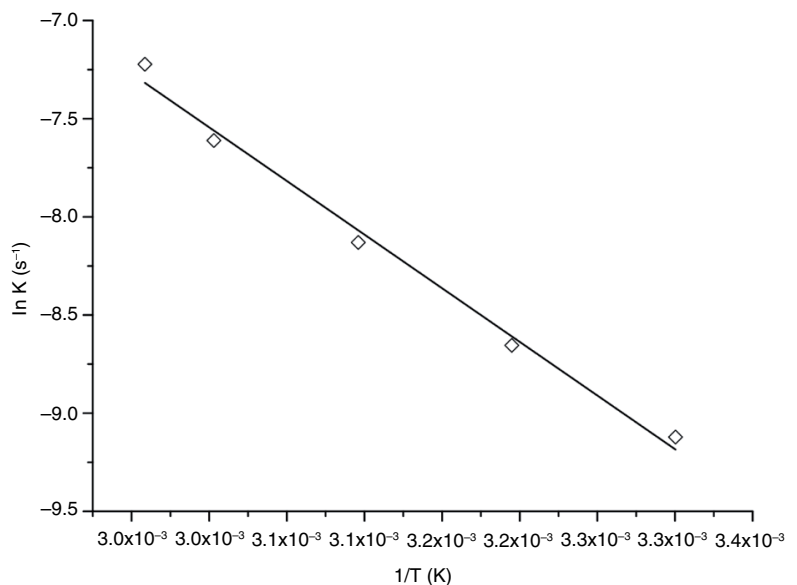

Figure 11. Plot between $\ln K$ and $1 / \mathrm{T}(\mathrm{K})$

where $\mathrm{A}$ is the frequency factor, Ea is activation energy $\left(\mathrm{kJ} \cdot \mathrm{mol}^{-1}\right)$, $\mathrm{T}$ is temperature $(\mathrm{K})$, and $\mathrm{R}$ is gas constant $\left(\mathrm{J} \cdot \mathrm{K}^{-1} \cdot \mathrm{mol}^{-1}\right)$.

The plot between $\ln \mathrm{K}$ and $1 / \mathrm{T}$ is used to calculate the energy of activation (Ea) (Sagir, Tan et al. 2013). The plot is shown in Figure 11. Linear regression of the plot gives the activation energy of the reaction as $45.42 \mathrm{~kJ}$ mol-1 which is very close to the value $\left(45 \mathrm{~kJ} \cdot \mathrm{mol}^{-1}\right.$ and $\left.51 \mathrm{~kJ} \cdot \mathrm{mol}^{-1}\right)$ as reported elsewhere (Berrios et al., 2007; Fernandes et al., 2012). The value $45 \mathrm{~kJ} \cdot \mathrm{mol}^{-1}$ for Ea was found by using $10 \%$ sulfuric acid as catalyst and $51 \mathrm{~kJ} \cdot \mathrm{mol}^{-1}$ was found by using 12-tungustophosphoric acid (1 $\mathrm{mol} \%$ ) (Fernandes, Cardoso et al., 2012) as the catalyst for the esterification of oleic acid. Furthermore, a similar value $\left(46.69 \mathrm{~kJ} \cdot \mathrm{mol}^{-1}\right)$ of activation energy was reported using $\mathrm{SnCl} 2$ catalyst to esterify oleic acid to methyl ester in soybean oil (Cardoso et al., 2008).

\section{CONCLUSION}

In this study three solid catalysts namely silica sulfuric acid (SSA), silica supported boron trifluoride (SSB) and a hybrid catalyst (HC), which was a 50-50 mixture of SSA and SSB, were evaluated for the esterification of high FFA in Jatropha curcas oil. Experimental results showed that the catalytic activity of the hybrid catalyst was superior to that of SSA and SSB alone. A very strong synergistic effect was noted in catalytic activity when the hybrid (mixed) catalyst was used, and an initial FFA value of $45.64 \%$ was reduced to $0.903 \%$, with $98 \%$ efficiency. The reaction conditions were optimized for the oil FFA:methanol mole ratio of $1: 15$, a reaction temperature of $65^{\circ} \mathrm{C}$ and a reaction time of 100 minutes. Furthermore, while using 2 wt. $\%$ of hybrid catalyst for oil samples with varying FFA values from 6.64 to $45.64 \%$, the FFA conversion to methyl esters was more than $98 \%$. The catalyst was found re-usable for three times for the oil with low FFA $(6.64 \%)$ values and was found relatively less attractive for re-using in the case of oil with a high FFA $(45.64 \%)$ value. The catalytic conversion reaction of FFA to methyl esters with this catalyst was found to follow the first order kinetics. Activation energy was calculated to be $45.42 \mathrm{KJ} \mathrm{mol}^{-1}$ for $2 \mathrm{wt} . \%$ of the hybrid catalyst. It is concluded that the studied hybrid catalyst can be used successfully to esterify natural oils to methyl esters for both high and low amounts of FFA and with good reusability potential for relatively low FFA oils.

\section{ACKNOWLEDGEMENT}

The authors gratefully acknowledge the financial support of PETRONAS Research Sdn. Bhd. (PRSB) through PRF Project 158200042 and the use of EOR Centre of Excellence facilities.

\section{REFERENCES}

Atadashi IM, Aroua MK, Abdul Aziz AR, Sulaiman NMN. 2012. Production of biodiesel using high free fatty acid feedstocks. Renewable Sustainable Energy Reviews 16, 3275-3285. http://dx.doi.org/10.1016/j.rser.2012.02.063

Berrios M, Siles J, Martin M, Martin A. 2007. A kinetic study of the esterification of free fatty acids (FFA) in sunflower oil. Fuel 86, 2383-2388. http://dx.doi.org/10.1016/j. fuel.2007.02.002

Borges ME, Díaz L. 2012. Recent developments on heterogeneous catalysts for biodiesel production by oil esterification and transesterification reactions: A review. Renewable and Sustainable Energy Reviews 16, 2839-2849. http:// dx.doi.org/10.1016/j.rser.2012.01.071

Cardoso A, Neves S, Da Silva M.2008. Esterification of Oleic Acid for Biodiesel Production Catalyzed by $\mathrm{SnCl2}$ : A Kinetic Investigation. Energies 1, 79-92. http://dx.doi. org/10.3390/en1020079

Chung KH, Chang DR. Park BG. 2008. Removal of free fatty acid in waste frying oil by esterification with methanol on zeolite catalysts. Bior. Technol. 99, 7438-7443. http:// dx.doi.org/10.1016/j.biortech.2008.02.031

Corro G, Tellez N, Ayala E, Marinez-Ayala A. 2010. Two-step biodiesel production from Jatropha curcas crude oil using $\mathrm{SiO} 2 \cdot \mathrm{HF}$ solid catalyst for FFA esterification step. Fuel $\mathbf{8 9}$, 2815-2821. http://dx.doi.org/10.1016/j.fuel.2010.04.023

Dhar A, Kevin R, Agarwal AK. 2012. Production of biodiesel from high-FFA neem oil and its performance, emission and combustion characterization in a single cylinder DICI engine. Fuel Process. Technol. 97,118-129. http://dx.doi. org/10.1016/j.fuproc.2012.01.012

Fernandes SA, Cardoso AL, da Silva MJ. 2012. A novel kinetic study of H3PW12O40 - catalyzed oleic acid esterification with methanol via $1 \mathrm{H}$ NMR spectroscopy. Fuel Processing Technol. 96, 98-103. http://dx.doi.org/10.1016/j. fuproc.2011.12.025

Gui MM, Lee KT, Bhatia S. 2008. Feasibility of edible oil vs. non-edible oil vs. waste edible oil as biodiesel feedstock. Energy 33, 1646-1653. http://dx.doi.org/10.1016/j. energy.2008.06.002

Guillén M, Cabo N.1997. Characterization of edible oils and lard by fourier transform infrared spectroscopy. Relationships between composition and frequency of concrete bands in the fingerprint region. J. Am. Oil Chem. Soc. 74, 12811286. http://dx.doi.org/10.1007/s11746-997-0058-4

Khalafi-Nezhad A, ParhamiA, Soltani RadMN, Zolfigol MA, Zare A. 2007. A catalytic method for chemoselective detritylation of $5^{\prime}$-tritylated nucleosides under mild and 
heterogeneous conditions using silica sulfuric acid as a recyclable catalyst. Tetrahedron Letters 48, 5219-5222. http://dx.doi.org/10.1016/j.tetlet.2007.05.153

Lee AF, Bennett JA, Manayil JC, Wilson K. 2014. Heterogeneous catalysis for sustainable biodiesel production via esterification and transesterification. Chem. Soc. Rev. 43, 7887-7916. http://dx.doi.org/10.1039/C4CS00189C

Leung DYC, Guo Y.2006. Transesterification of neat and used frying oil: Optimization for biodiesel production. Fuel Processing Technol. 87, 883-890. http://dx.doi. org/10.1016/j.fuproc.2006.06.003

Mushtaq M, Tan IM, Ismail L, Lee SYC, Nadeem M, Sagir M.2013. Oleate Ester-Derived Nonionic Surfactants: Synthesis and Cloud Point Behavior Studies. J. Disp. Sci. Technol. 35, 322-328. http://dx.doi.org/10.1080/01932691. 2013.783492

Mushtaq M, Tan IM, Nadeem M, Devi C, Lee SYC, Sagir M. 2014. A Convenient Route For The Alkoxylation Of Biodiesel And Its Influence On Cold Flow Properties. Int J. Green Energy 11, 267-279. http://dx.doi.org/10.1080/154 35075.2013.772519

Mushtaq MT, Nadeem IM, Devi C, Lee, SYC, Sagir M, Rashid U. 2013. Epoxidation of methyl esters derived from Jatropha oil: an optimization study. Grasas Aceites 64, 103-114. http://dx.doi.org/10.3989/gya.084612

Nakpong P, Wootthikanokkhan S. 2010. High free fatty acid coconut oil as a potential feedstock for biodiesel production in Thailand. Renewable Energy 35, 1682-1687. http:// dx.doi.org/10.1016/j.renene.2009.12.004

Otadi M, ShahrakiA, Goharrokhi M, Bandarchian F. 2011. Reduction of Free Fatty Acids of Waste Oil by AcidCatalyzed Esterification. Procedia Eng. 18, 168-174. http:// dx doi.org/10.1016/j.proeng .2011.11.027

Sagir M, Tan IM, Mushtaq M, Ismail L, Nadeem M, Azam MR, Hashmet MR. 2013. Novel Surfactant for the Reduction of CO2/Brine Interfacial Tension. J. Dispersion Sci. Technol. 35, 463-470. http://dx.doi.org/10.1080/01932 691.2013.794111

Sagir M, Tan IM, Mushtaq M, Nadeem M. 2013. CO2 Mobility and $\mathrm{CO} 2 /$ Brine Interfacial Tension Reduction by Using a New Surfactant for EOR Applications.Journal of Dispersion Science and Technol. 35, 1512-1519. http:// dx.doi.org/10.1080/01932691.2013.859087
Shahid EM, Jamal Y. 2011. Production of biodiesel: A technical review. Renewable Sustainable Energy Reviews 15, 47324745. http://dx.doi.org/10.1016/j.rser.2011.07.079

Supamathanon N, Wittayakun J, Prayoonpokarach S. 2011. Properties of Jatropha seed oil from Northeastern Thailand and its transesterification catalyzed by potassium supported on $\mathrm{NaY}$ zeolite. J. Indus. Eng. Chem. 17, 182-185. http://dx.doi.org/10.1016/j.jiec.2011.02.004

Syam AM, Yunus R, Hamid HA, Al-Resayes SI, Nehdi IA, Al-Muhtaseb AH. 2016. Conversion of Oleum papaveris seminis oil into methyl esters via esterification process: Optimization and kinetic study. Grasas Aceites 67, e115. doi: http://dx.doi.org/10.3989/gya.0496151

Um B-H, Kim Y-S. 2009. Review: A chance for Korea to advance algal-biodiesel technology. J. Indus. Eng. Chem. 15, 1-7. http://dx.doi.org/10.1016/j.jiec.2008.08.002

WangY, Pengzhan Liu SO, Zhang Z. 2007. Preparation of biodiesel from waste cooking oil via two-step catalyzed process. Ener. Conversion Management 48, 184-188. http:// dx.doi.org/10.1016/j.enconman.2006.04.016

Wilson K, Clark JH. 1998. Synthesis of a novel supported solid acid BF3 catalyst. Chem. Comm. 19, 2135-2136. http:// dx.doi.org/10.1039/a806060f

Wilson R, Smith R, WilsonP, Shepherd MJ, RiemersmaRA. 1997. Quantitative gas chromatography-mass spectrometry isomer-specific measurement of hydroxy fatty acids in biological samples and food as a marker of lipid peroxidation. Anal. Biochem. 248, 76-85. http://dx.doi.org/10.1006/ abio.1997.2084

Yin P, ChenL, WangZ, QuR, Liu X, Ren S. 2012. Production of biodiesel by esterification of oleic acid with ethanol over organophosphonic acid-functionalized silica. Bior. Technol. 110, 258-263. http://dx.doi.org/10.1016/j. biortech.2012.01.115

Zhang J, Jiang L. 2008. Acid-catalyzed esterification of Zanthoxylum bungeanum seed oil with high free fatty acids for biodiesel production. Bioresour Technol. 99, 8995-8998. http://dx.doi.org/10.1016/j. biortech.2008.05.004

Zhou H, Lu H, Liang B. 2006. Solubility of Multicomponent Systems in the Biodiesel Production by Transesterification of Jatropha curcas L. Oil with Methanol. J. Chem. Eng. Data 5, 1130-1135. http://dx.doi.org/10.1021/je0600294 